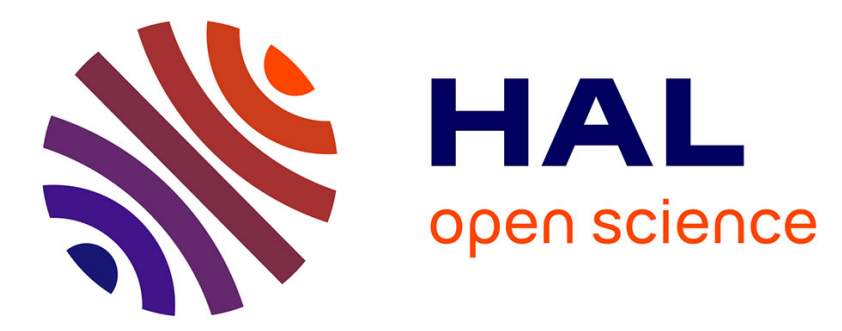

\title{
Impact of a distant wildland fire on an LPG tank
}

Frederic Heymes, Laurent Aprin, Serge Forestier, Pierre Slangen, Jean

Baptiste Jarry, Henri François, Gilles Dusserre

\section{To cite this version:}

Frederic Heymes, Laurent Aprin, Serge Forestier, Pierre Slangen, Jean Baptiste Jarry, et al.. Impact of a distant wildland fire on an LPG tank. Fire Safety Journal, 2013, 61, pp.100-107. 10.1016/j.firesaf.2013.08.003 . hal-02012122

\section{HAL Id: hal-02012122 \\ https://hal.science/hal-02012122}

Submitted on 24 Feb 2020

HAL is a multi-disciplinary open access archive for the deposit and dissemination of scientific research documents, whether they are published or not. The documents may come from teaching and research institutions in France or abroad, or from public or private research centers.
L'archive ouverte pluridisciplinaire HAL, est destinée au dépôt et à la diffusion de documents scientifiques de niveau recherche, publiés ou non, émanant des établissements d'enseignement et de recherche français ou étrangers, des laboratoires publics ou privés. 


\title{
Impact of a distant wildland fire on an LPG tank
}

\author{
Frederic Heymes ${ }^{\mathrm{a}, *}$, Laurent Aprin ${ }^{\mathrm{a}}$, Serge Forestier ${ }^{\mathrm{a}}$, Pierre Slangen ${ }^{\mathrm{a}}$, Jean Baptiste Jarry ${ }^{\mathrm{b}}$, \\ Henri François $^{\mathrm{b}}$, Gilles Dusserre ${ }^{\mathrm{a}}$ \\ a LGEI, Ecole des Mines d'Alès, 6 avenue de Clavières, 30319 Ales, France \\ b Comité Français du Butane et du Propane, 8, terrasse Bellini, 92807 Puteaux cedex, France
}

\section{A B S T R A C T}

During wildland fires, homes located close to the fire can be threatened by the thermal heat flux from the firewall. Several studies have attempted to establish safety distances to protect people and prevent houses from burning, but no research has focused on the possible presence of an LPG tank, which would be supplying fuel for heating or cooking. This topic is, however, very important since hazards from a BLEVE (blast, fireball, fragments) can hurt firefighters during their intervention. This article aims to analyze the impact of a large crown fire on an LPG tank, if a mandatory safety zone of fifty meters is respected. Part One focuses on theoretical considerations aiming to (i) calculate the radiative heat fluxes impacting the tank, and (ii) perform a real scale test. Experiments were performed with a $2 \mathrm{~m}^{3} \mathrm{LPG}$ tank $15 \%$ full, with a heat flux from a natural gas burner system. The relevance of these test versus a real case is discussed. Results are in very good agreement with the expected heat fluxes, and suggest that there should be no BLEVE risk in the hypothetical conditions.

Keywords:

Wildland fire

LPG Tank

Boiling liquid expanding vapor cloud

explosion

BLEVE

Fire safety

\section{Introduction}

Research on wildland fires traditionally focuses on two objectives. First, predicting the velocity at which a fire will spread, and second, the heat released by the fire, and the impact on targets located close to it. The latter point is useful to study in order to establish safety distances, which enable safety zones to be defined for people (e.g., firefighters), residential houses, and other buildings (e.g., factories and schools). Such zones must be established on the basis of thermal heat transfer from fire to the target as well as the behavior of the impacted target.

In the case of wildland fires, radiative heat transfer is an important component of the heat transfer to the target. Convection is not usually taken into account in terms of the effects on people and structures. As Indicated by Gentle and Rice [1], the convective transfer to structures and the radiative heat transfer from flames must be better evaluated in the technical literature. Zarate et al. [7] explain that convective transfer is an important point in the spreading of fire, but not from the point of view of heat transfer to a point remote from fire. Noteworthy studies on radiative heat transfer from wildland fires include Tran et al. [2], Butler and Cohen [3,4], Sullivan et al. [5], Billaud et al. [6] and Zarate et al. [7].

\footnotetext{
* Corresponding author. Tel.: +33 466782 729; fax: +33466 782701 .

E-mail address: fheymes@mines-ales.fr (F. Heymes).
}

Liquefied Petroleum Gas (LPG) is a common fuel used for home heating, hot water production, and cooking. This fuel is usually stored outside of the house in medium capacity pressurized cylindrical tanks ( 1 or $2 \mathrm{~m}^{3}$ ). These tanks are not protected against fire by a passive protection layer, but a relief valve prevents excessive pressure from building up in them. However, when such a tank is exposed to external fire, there is a chance that the tank will fail despite the role played by the pressure relief valve $[8,9]$. If the failure mode is catastrophic, then this could lead to a boiling liquid expanding vapor explosion (BLEVE).

The physics of this phenomenon are as follows: The impacting heat flux leads to a higher wall temperature, thereby weakening the wall. Heat it also transferred to the liquid phase, which increases the temperature of the liquid and the vapor pressure. This internal pressure increase leads to irreversible deformation and thinning in the hot wall area, and this may eventually lead to the formation of a tear or fissure in the tank wall. If the tear propagates the entire length of the tank, then a BLEVE takes place. If the fissure stops short, then a transient jet release takes place.

The immediate hazards of a BLEVE are a blast [10] and projectiles [11]. Since LPG is flammable, it will be ignited immediately and a fireball is possible with the associated hazards of fire engulfment and thermal radiation [12]. If the flammable commodity is not ignited immediately, then delayed ignition may lead to widespread fires or in some cases explosions (vapor cloud explosion). If an LPG tank fails, these hazards may hurt or kill firemen fighting a wildfire in a residential area, especially if they are not aware of the presence of an LPG tank. In several countries, the law obliges homeowners to 


\begin{tabular}{|c|c|c|c|}
\hline \multicolumn{2}{|c|}{ Nomenclature } & $T$ & flame temperature $(\mathrm{K})$ \\
\hline$A$ & area of the emitting surface $\left(\mathrm{m}^{2}\right)$ & RHF & radiative heat flux $\left(\mathrm{kW} \mathrm{m}^{-2}\right)$ \\
\hline$B$ & area of the receiving surface $\left(\mathrm{m}^{2}\right)$ & SEP & Surface emissive power $\left(\mathrm{kW} \mathrm{m}^{-2}\right)$ \\
\hline $\mathrm{d} A, \mathrm{~d} B$ & differential surface area, $\left(\mathrm{m}^{2}\right)$ & THF & total heat flux on the tank, $\mathrm{kW}$ \\
\hline$D$ & diameter of the LPG $\operatorname{tank}(\mathrm{m})$ & $x$ & distance between fire and target wall (m) \\
\hline E & surface emissive power (SEP) $\left(\mathrm{kW} \mathrm{m}^{-2}\right)$ & & \\
\hline $\mathrm{F}$ & view factor $(-)$ & \multirow{2}{*}{\multicolumn{2}{|c|}{ Greek letters }} \\
\hline$H$ & flame height (m) & & \\
\hline$L$ & length of fire $(\mathrm{m})$ & $\varepsilon$ & emissivity of the flame (-) \\
\hline $\begin{array}{l}l \\
q\end{array}$ & $\begin{array}{l}\text { length of LPG tank }(\mathrm{m}) \\
\text { heat transferred to the target }\left(\mathrm{kW} \mathrm{m}^{-2}\right)\end{array}$ & $\tau$ & $\begin{array}{l}\text { transmittivity of the air (of gas) layer between the } \\
\text { flame and the target (-) }\end{array}$ \\
\hline$R$ & $\begin{array}{l}\text { Distance between the emitting and the receving } \\
\text { surfaces }(m)\end{array}$ & $\begin{array}{l}\sigma \\
\theta\end{array}$ & $\begin{array}{l}\text { Stefan Boltzmann constant } 5.67 \times 10^{-8} \mathrm{~J} \mathrm{~s}^{-1} \mathrm{~K}^{-4} \mathrm{~m}^{-2} \\
\text { angle between the normal vector and direction vector } \\
(-)\end{array}$ \\
\hline
\end{tabular}

clear the undergrowth within a distance from their house in order to stop the fire and prevent it from burning the house. For example, in France this safety distance is $50 \mathrm{~m}$, in Spain it is $25 \mathrm{~m}$, in the US in high-risk areas it is 100 feet $(30 \mathrm{~m})$.

If a wildfire occurs near a house that uses LPG, will a BLEVE occur? Will the pressure relief valve open? The worst situation would occur during a crown fire, which is the most intense fire scenario.

This paper describes the behavior of a cylindrical tank, filled with LPG, when impacted by a large wildland crown fire that comes within $50 \mathrm{~m}$ of the tank. The paper is divided into three main parts. The first part deals with the finite element (FE) modeling developed during this research in order to calculate the radiative heat flux impacting the tank during a crown fire event. A discussion is also proposed on the scaling factor of the firewall from the forest fire scale to a medium size burner firewall scale. This work enabled a real scale experiment to be designed with respect to thermal criteria. The second part presents the experimental set-up performed with a system of natural gas burners and the experimental data collected. Finally, results are discussed in the last part, and a conclusion drawn about the safety of an LPG tank that is affected by a forest fire.

\section{Theoretical part}

\subsection{Wildland fire radiation modeling}

Modeling the radiative heat flux from a wildland fire to a target requires knowledge of the emitted radiation power of the fire and a calculation of the transmission of the radiative energy to the target in terms of view factor considerations [13]. The first task is tricky since the emitted power depends on many variables, such as flame combustion kinetics and temperature, flame thickness, and the emissivity of gases and soot. A popular approach to the estimation of the radiation flux from wildland fires is the use of the solid flame model (SFM). In this model, the visible flame is idealized as a solid body, with a simple geometrical shape, and with thermal radiation emitted from its surface. The contribution of non-visible zones of the fire plume to the radiative heat flux is usually not taken into account. Although several authors [14,15], suggest that this model may be questionable for wildland fires, the SFM model is easy to use and gives results in acceptable agreement with experimental data [4]. In the SFM, the radiative heat flux per unit area reaching a remote target is given by:

$q=\tau \cdot F \cdot E$ where $F$ is the view factor, E the surface emissive power (SEP) of the visible flame, and $\tau$ the transmittivity of the air (or combustion gases) layer between the flame and the target. The atmospheric transmittivity corresponds to the fraction of thermal radiation that is transmitted from the fire to the target; it is a function of atmospheric humidity, the concentration of carbon dioxide, and distance, and can be calculated using semi-empirical equations. The worst case occurs when the transmittivity is 1 . The surface emissive power of the flame may be calculated as:

$$
E=\varepsilon . \sigma \cdot T^{4}
$$

where $\varepsilon$ is the effective emissivity of the flame, $T$ is the flame temperature, and $\sigma$ is the Stefan Boltzmann constant. Data about SEP values can be found in the literature, the most valuable of them was measured during the International Crown Fire Modeling Experiments (ICFME) [4]. These authors measured SEP on large crown fires of Jack pine trees (average height $12 \mathrm{~m}$ ) in forest squares (75-200 m side length). SEP measurements were taken at different heights: $3.1,6.2,9.2,12.3$, and $13.8 \mathrm{~m}$. We averaged the data measured at theses heights in 6 experiments, and concluded that the maximum peak radiative flux was nominally $190 \mathrm{~kW} \mathrm{~m}^{-2}$ throughout the entire stand, with a standard deviation of $90 \mathrm{~kW} \mathrm{~m}^{-2}$. However, these values are only valid during the maximum fire intensity, which lasts a few seconds. When considering the effect of wildland forest fire radiation on an LPG tank, the amount of time taken into account is much longer since the heat transfers and thermal inertia of fluids and steel are slower, and a minimum time of several minutes is required in order to make the internal pressure increase. When averaging Butler data over the time during which the fire is significant $\left(\mathrm{SEP}>20 \mathrm{~kW} \mathrm{~m}^{-2}\right)$, it appears that the average heat flux is reduced to $70 \mathrm{~kW} \mathrm{~m}^{-2}$. Others SEP values can be found in the literature, such as $57 \mathrm{~kW} \mathrm{~m}^{-2}$ [6], $118 \mathrm{~kW} \mathrm{~m}^{-2}$ [3,7], $90 \mathrm{~kW} \mathrm{~m}^{-2}$ [16], $60 \mathrm{~kW} \mathrm{~m}^{-2}$ [17], $59 \mathrm{~kW} \mathrm{~m}^{-2}$ [18]. In this study, we consider $90 \mathrm{~kW} \mathrm{~m}^{-2}$ to be realistic.

The amount of time during which an LPG tank will be affected by the radiative heat flux emitted from a wildfire depends on many considerations such as wind velocity, spreading rate, geometric considerations, canopy massiveness and humidity. Billaud et al. [6] modelled the heat flux impacting a house located $50 \mathrm{~m}$ from a spreading wildfire and showed that the target could be impacted for $600 \mathrm{~s}$ with variable intensity. Therefore, and to consider the worst case, a total exposition time of 20 min was used for the experimental part of our research.

The view factor $F$ is defined as the fraction of the radiation leaving a surface $A$ that is intercepted by a surface $B$. Oriented elementary areas ad and $\mathrm{d} B$ are connected by a line of length $R$, 
which forms the polar angles $\theta_{A}$ and $\theta_{B}$, respectively, with the surface normal vectors $\mathbf{n}_{A}$ and $\mathbf{n}_{A}$. The values of $R, \theta_{A}$ and $\theta_{B}$ vary in function of the position of the elemental areas on $A$ and $B$. Assuming that both surfaces emit and reflect diffusely, and that the radiosity is uniform, the view factor can be defined as:

$F_{A B}=\frac{1}{A} \int_{A} \int_{B} \frac{\cos \theta_{A} \cos \theta_{B}}{\pi R^{2}} d A d B$

The heat flux emitted by surface A and received by surface B is then calculated from Eq. (1). Three different types of methods can be used to calculate or approximate this double integral. The first one is the exact or approximate analytical solution of the equation. This is the easiest way to proceed, but analytical solutions were only proposed in simple configurations [19-21]. The second method is a finite element method (FE method), the accuracy of which depends mainly on the mesh size. This method of computing is time consuming since the total number of calculation steps corresponds to the multiplication of the number of cells of $A_{\mathrm{i}}$ by $A_{j}$. The last approach relies on the Monte Carlo method (MC), which reduces the computational time by reducing stochastically the number of calculations in order to approximate the double integral. Billaud et al. explain this method [6], and compare its accuracy with an analytical equation in simple cases: good agreement was found. The last two methods are compromises between accuracy and computation time, a specific sensitivity analysis has to be performed in order to choose the better compromise. In complicated but small systems for which no analytical solution was found, FE modeling can be considered. But in large geometrical systems like spreading wildfires or impact on houses, the FE method will require calculations too long to be completed, so the Monte Carlo method should be preferred.

The geometric configuration considered in this work (Fig. 1) is quite simple, but no analytical equation was found in the literature. The FE method was therefore selected in order to approximate the heat flux impacting the LPG tank. The FE solution to the previous equation is achieved by meshing the A surface into i cells $\left(\mathrm{d} A_{i}\right)$ and the $B$ surface into $j$ cells $\left(\mathrm{d} B_{j}\right)$. The equation can be written as:

$F_{A B}=\frac{1}{A} \sum_{i} \sum_{j} \frac{\cos \theta_{A i} \cos \theta_{B j}}{\pi R_{i j}^{2}} d A_{i} d B_{j}$

In this paper, surface $A$ represents the fire while $B$ represents the LPG tank. Its accuracy depends strongly of the size of the cells, and therefore the number of cells, which is time consuming.

\subsection{LPG tank behavior}

Modeling the thermo-hydraulic behavior of an LPG tank requires a comprehensive study of the heat and mass transfer processes involved in the tank, in order to be able to accurately predict how the tank temperatures and pressure will vary over time during the fire. It is then possible to predict under what conditions failure of such tanks may occur, sometimes resulting in BLEVE. Many studies have been completed in order to model this thermo-hydraulic system more or less successfully. These models enable the tank's thermal state to be calculated during a dynamic phenomenon, like non steady combustion or a spreading fire.

However, to determine the safety conditions in which an LPG tank will not BLEVE, it is not necessary to achieve full modeling. The usual way for determining the safety criteria for LPG tanks is in terms of maximum permissible values, whatever the fire scenario or the wear of the tank. In fact, the key points for safety evaluation are (1) the maximum wall temperature reached in the tank, and (2) the change in internal pressure.

The maximum temperature of the steel wall depends on the radiative heat flux impacting it, the internal and external convection with fluids in contact with the wall, the radiative heat flux emitted by the steel, and the conductive heat transfer in it. Since the convective heat transfer is higher with a liquid phase than a gas phase, and since LPG will warm much more slowly than the gas phase, the hottest point of steel is always located on unwetted steel.

Therefore, this study only considers the maximum radiative heat flux on the tank $\left(\mathrm{kW} \mathrm{m}^{-2}\right)$ and the total heat flux impacting the tank (kW). The latter value is directly linked with the internal pressure increase since most of the heat received by the steel walls will be transferred into the liquid phase by convection and radiation in the tank. The first value determines the increase in the temperature of the steel, which should remain under a certain safety value. In case of an LPG tank equipped with an adequate pressure relief valve, the internal pressure should not exceed $17 \mathrm{barg}$. In Canada or the United States, the tank is considered to be safe if the temperature of the steel does not exceed $427{ }^{\circ} \mathrm{C}$ for a long time ( $30 \mathrm{~min}$ of exposition in the case of a jetfire, and $100 \mathrm{~min}$ for a poolfire).

\section{Theoretical design test}

Aside from the modeling, experimental work was performed to measure the behavior of an LPG tank during a crownfire. Since it is very difficult to create a real large crown fire that affects an LPG-

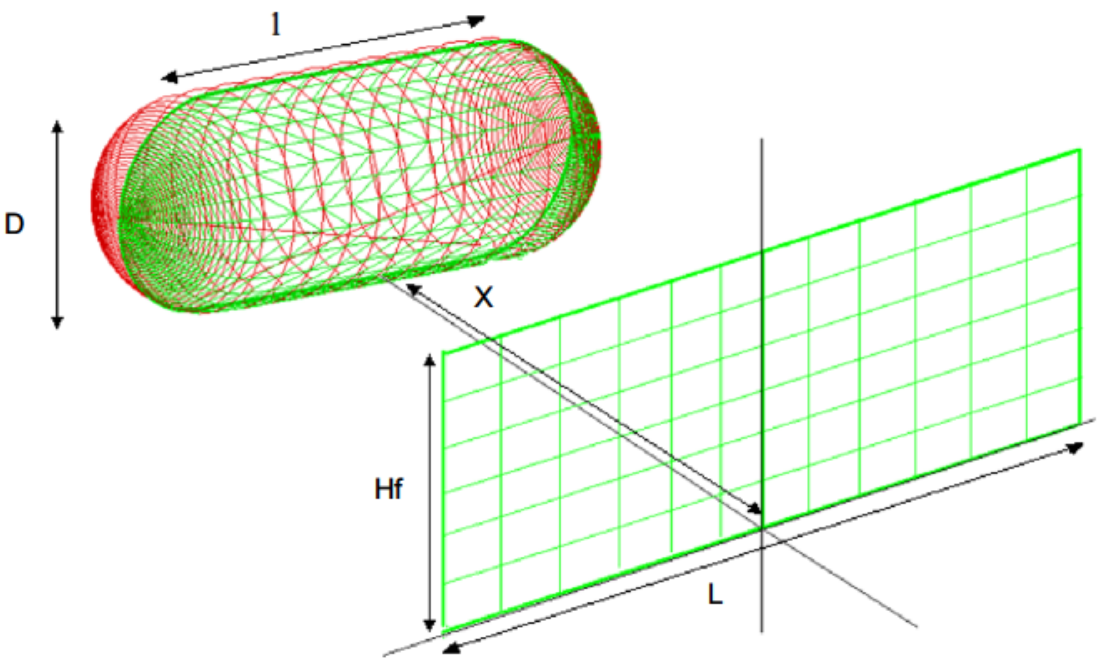

Fig. 1. Configuration of the thermal system. 
filled tank experimentally, a scaled experiment was performed. A medium scale fire set-up was designed to simulate a crown fire. The firewall was be achieved by a burning wall of natural gas burners (Fig. 7). Therefore, the experimental fire height could not exceed $4 \mathrm{~m}$, because of practical considerations. The size of the firewall, and the distance between the fire and the tank required rigourous analysis of the scaling effects.

\subsection{Configuration of the system}

The configuration analyzed is drawn in Fig. 1. The wildland fire is assumed to be correctly represented by a rectangular solid firewall and faces a horizontal $2 \mathrm{~m}^{3}$ LPG tank (diameter $D=1 \mathrm{~m}$, length $l=3.2 \mathrm{~m}$ ): the firewall and LPG tank were parallel to each other. The fire is supposed to be deep enough to behave as a black body $(\varepsilon=1)$. The average SEP is assumed to be $90 \mathrm{~kW} \mathrm{~m}^{-2}$, which corresponds to an average flame temperature of $850{ }^{\circ} \mathrm{C}$. This configuration was chosen in order to calculate the maximum heat flux (MHF) and total heat flux (THF) that would impact a $2 \mathrm{~m}^{3}$ LPG tank if it were exposed to a large crown fire. We assumed that the maximum size of the fire would be a total flame height of $40 \mathrm{~m}$ and a firewall length of $100 \mathrm{~m}$. The distance between the fire and the tank wall was defined as $50 \mathrm{~m}$.

Since the tank is supposed to be located far from the fire, the heat transfer between the firewall and the tank is assumed to be only radiative. Therefore, geometrical scaling is sufficient to design the experimental set-up. This scaling is partial: indeed, the tank will remain at scale 1 , while the firewall size will be strongly reduced (Fig. 2). Some distorsion in scaling can therefore be expected, and FE modeling was used to properly design that scaling.

\subsection{Validation of FE modeling}

Before scaling the set-up, we had to check the validity of the FE modeling used. A relevant case study was found in [6]. This case study is a 20 -m-wide vertical planar flame front (surface $A$, height $=H_{f}$ ), and a vertical small surface element (surface $B$ ) located in front of the flame center at a variable distance from the flame. The receiving element is located at a distance of $x=15 \mathrm{~m}$ from the flame front. Fig. 4 represents the view factor $F_{B A}$ : the fraction of radiation leaving surface $B$ that is intercepted by surface $A$. The closer $A$ is to $B$, the higher the view factor will be. Using finite elements modeling, the view factor $F_{B A}$ was calculated

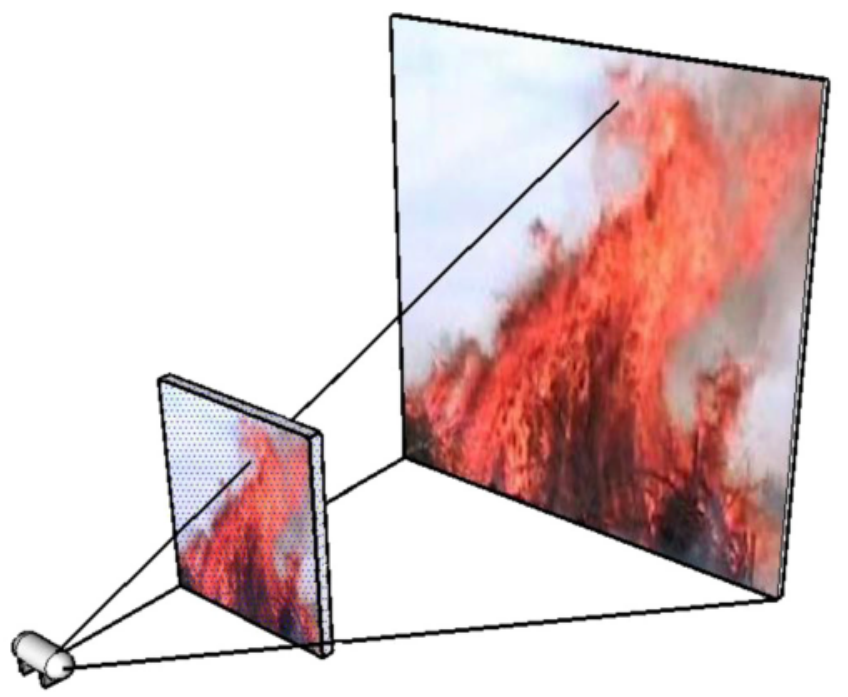

Fig. 2. Scaling of the system. by considering Eq. (4) and the reciprocity relation between $F_{A B}$ and $F_{B A}$ :

$F_{B A}=\frac{1}{d B} F_{A B}=\sum_{i} \sum_{j} \frac{\cos \theta_{A i} \cos \theta_{B j}}{\pi R_{i j}^{2}} d A_{i}$

This equation has the advantage of being independent of the size of elementary surface B. First, sensitivity analysis was performed in order to check the best compromise for solving the heat transfer problem using finite elements (Fig. 3). Surface A $(20 \mathrm{~m} \times 40 \mathrm{~m})$ was divided into cells (10 million cells), each cell exchanging a single ray to the target. The density of rays was 12,500 rays per square meter of surface $A$. This enables the view factor between both surfaces to be calculated. The high density of rays was then decreased, and the error with the initial calculation is reported in Fig. 3. This figure shows that a very small difference is observed when decreasing the number of rays. However, a level of 1 million cells was considered since the computing time was satisfactory ( $<1 \mathrm{~min}$ ).

The view factor $\mathrm{F}$ was calculated at different $\mathrm{x} / \mathrm{H}_{\mathrm{f}}$ ratios with two McGuire analytical equations (MG1 and MG2 [19]), the analytical equation of Van den Bosch and Weterings [21], the MC calculation of Billaud et al. [6], and the FE modeling (this study). Results are reported in Fig. 4. The FE modeling results correspond exactly to McGuire's analytical solution. The Monte Carlo modeling proposed by Billaud et al. was discussed by the authors; the same trend is observed but a significant difference is also observed. The worse modelings are from the MG1 and VW solutions, and should therefore not be used for the scaling. Another comparison of FE modeling with previous models is presented in Fig. 5, where the accuracy of the FE model with distance and flame height is reported. Again, the FE modeling results correspond exactly with McGuire's analytical solution of, whatever the distance and height of surface A. The MC model is in very good agreement for all fire heights when the fire is very far from the tank $(x=40 \mathrm{~m})$. The closer the tank is to the fire, the higher the deviation is between the models. At five meters, the deviation is $20 \%$ between the MC model and the other two models.

The FE model was then employed in order to calculate the impacting heat flux on the LPG tank at any point of the external surface (including both elliptical caps at the sides) (Fig. 1) for any fire scenario. The results can be drawn on a 3D sketch included in Fig. 6. This sketch clearly shows the zone that is mainly exposed to the firewall radiative heat flux. The detailed data calculated by the FE method were then processed in order to calculate the maximum heat flux on the tank (MHF, $\mathrm{kW} \mathrm{m}^{-2}$ ), and the total heat flux on the tank (THF, kW).

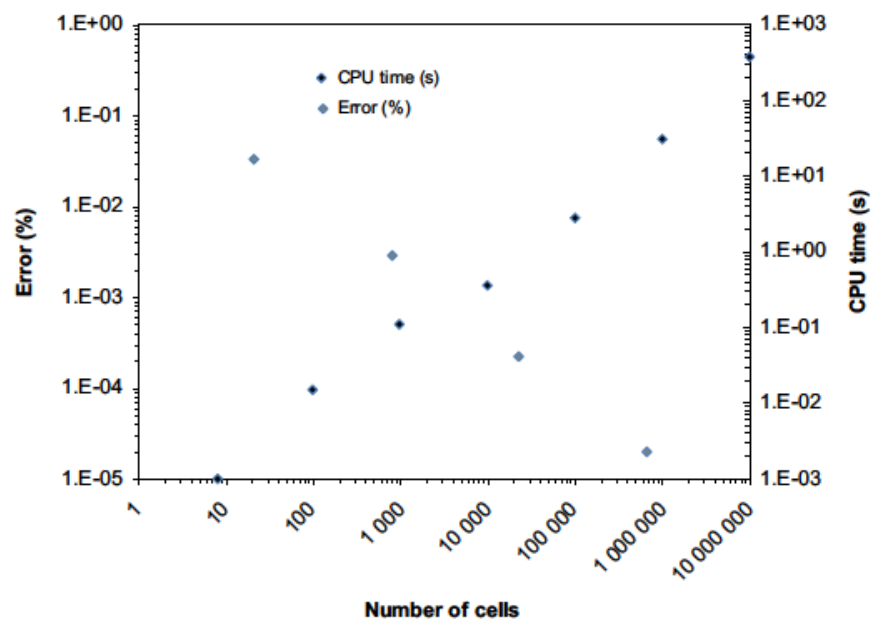

Fig. 3. Cells number sensitivity study (error, time). 


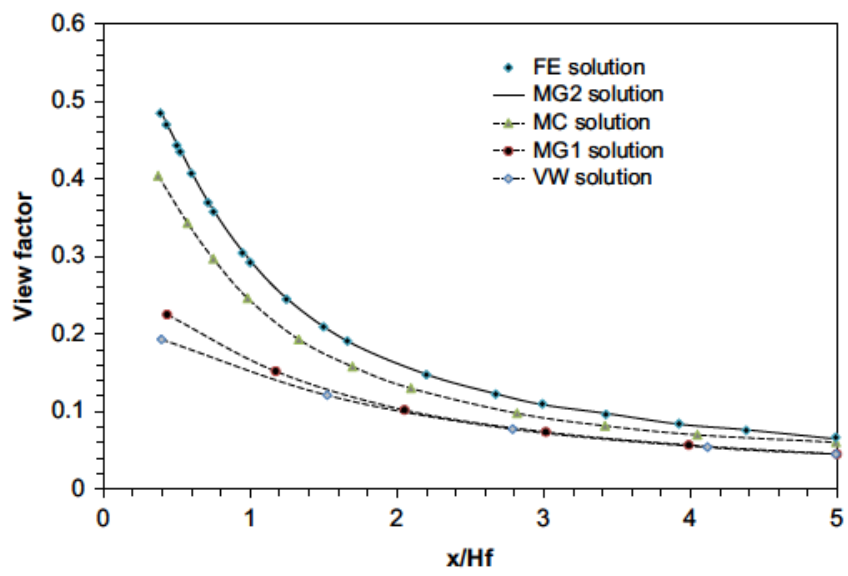

Fig. 4. Comparison of different view factor calculations at different $x / H f$ ratios.

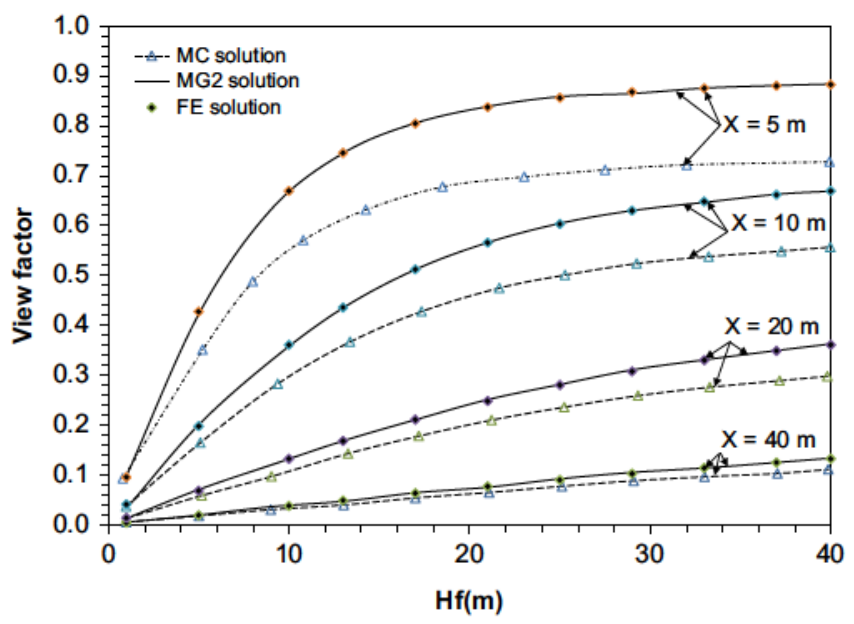

Fig. 5. Comparison of McGuire, MC and FEM view factor calculation.

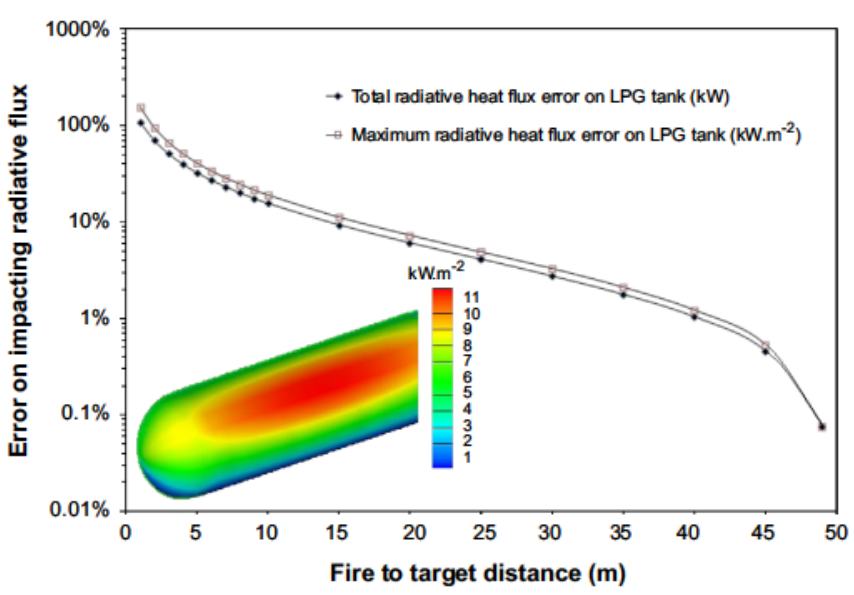

Fig. 6. 3D sketch and error calculation of the scaling.

\subsection{Scaling of the system to design the experiment}

We must remember that the objective of this study was to analyze theoretically but also experimentally the impact of a wildfire on an LPG tank, when the fire is $50 \mathrm{~m}$ from the tank. Medium scale experiments were required to record the behavior of the tank when there is a distant fire. The experiment was designed with the use of the FE modeling presented here.
A first scaling can be achieved using homothety. The height/length ratio of the firewall will be kept constant at different distances, but since the tank is not scaled simultaneously, it will change all angles of the rays exchanged between the fire and the tank.

In order to check if this scaling error is acceptable, MHF and THF were calculated at variable distances between the tank and the firewall, by considering simple homothety and by comparing FE modeling results at $50 \mathrm{~m}$ with results at the other different distances $x$. A preliminary study not reported here enabled us to choose a relevant meshing of the surfaces in order to achieve an acceptable error level. With the parameters given in Table 1, the error is lower than $0.1 \%$ (computation of $2 \times 10^{8}$ rays).

Fig. 6 reveals that scaling using homothety is quite acceptable at a distance higher than $20 \mathrm{~m}$ (error lower than 10\%). The more this distance is reduced, the more significant the error is, and a simple homothety is no more relevant. Considering that the experimental firewall should not be too high for practical reasons ( $<4 \mathrm{~m}$ ), it will be necessary to put it as close as possible to the tank. At $2 \mathrm{~m}$, the error is $100 \%$, which reflects the high geometric distorsion between the reduced firewall and the real size tank. The experimental set-up cannot be scaled with such an error.

To correct this scaling error and design the best size firewall in order to link MHF and THF criteria, other configurations were investigated. A large set of calculations was performed to find the best height, length, and distance of the smaller firewall to respect scaling criteria. The height varied in the $[0.5-4 \mathrm{~m}]$ range and the length in the [2-20 m] range. The distance had to be a compromise between scaling agreement and experimental limits. It was found to be impossible to scale the firewall correctly at a distance of less than $4 \mathrm{~m}$. This value was chosen for scaling.

Investigations of height and lengths were made with $0.1 \mathrm{~m}$ steps. Good agreement was found with a height of $4 \mathrm{~m}$ and a length of $8 \mathrm{~m}$, and $4 \mathrm{~m}$ from the tank. With these dimensions, the MHF was overestimated by $18 \%$ whereas the THF was overestimated by only 7.5\%. By considering that the SEP equals $90 \mathrm{~kW} \mathrm{~m}^{-2}$, both real and scaled scenarios can be compared from a theoretical point of view (Table 2). The MHF and THF are quite similar, with higher values of the scaled experiments, which is good since it is a worst case scenario. If experiments correspond exactly to the theoretical design, the MHF should be $29 \mathrm{~kW} \mathrm{~m}^{-2}$, and the THF, $90 \mathrm{~kW}$.

Table 1

FEM parameters to calculate the heat flux on the LPG tank.

\begin{tabular}{|c|c|c|}
\hline & Firewall & LPG tank \\
\hline $\begin{array}{l}\text { Number of elements } \\
\text { Numbers of calculated rays }\end{array}$ & 9800 & 22,000 \\
\hline Size of elements (m) & $\begin{array}{l}\text { Side } 10.28 \\
\text { Side } 20.28\end{array}$ & $\begin{array}{l}\text { Straight side } 0.16 \\
\text { Curved side } 0.031\end{array}$ \\
\hline Computing time & $\begin{array}{l}42 \mathrm{~s} \text { with a processor } \\
\mathrm{CPU} 3.06 \mathrm{GHz}\end{array}$ & \\
\hline
\end{tabular}

Table 2

Comparison of real scale and reduced scale scenarios.

\begin{tabular}{lll}
\hline & Real scale & Reduced scale \\
\hline Firewall height $(\mathrm{m})$ & 40 & 4 \\
Firewall length $(\mathrm{m})$ & 100 & 8 \\
Firewall SEP $\left.(\mathrm{kW} \mathrm{m})^{-2}\right)$ & 90 & 90 \\
Distance fire $-\operatorname{tank}^{(\mathrm{m})}$ & 50 & 4 \\
Calculated MHF(kW m $\left.{ }^{-2}\right)$ & 24 & 29 \\
Calculated THF $(\mathrm{kW})$ & 84 & 90 \\
\hline
\end{tabular}




\section{Experimental set-up}

Experiments were performed in April 2011 at the Spadeadam test site, GL Noble Denton, UK. A $2 \mathrm{~m}^{3}$ tank was $15 \%$ filled with commercial LPG. The gas burner system was designed with 5 horizontal tubes pierced with two rows of holes. The final dimensions of the firewall were $8 \mathrm{~m}$ by $3 \mathrm{~m}$. The flames beyond the firewall had an average height of $4 \mathrm{~m}$. A mild steel plate was fixed behind the fire in order to homogenize and increase the emitted radiative heat flux. These plates resulted in a lack of oxygen and promoted the formation of soot. The natural gas flames were clearly yellow. A picture taken during the experiment is given in Fig. 7.

Before putting the tanks in front of the fire for the real test, several experiments with radiative heat flux meters were performed to check the best distance. It was found that $3.8 \mathrm{~m}$ met the scaling criteria better than $4 \mathrm{~m}$, so the tank was then put $3.8 \mathrm{~m}$ away from the firewall.

The LPG tank was equipped with standard equipments (pressure relief valve, level gauge, inlet and outlet valves). The structure of the tank was not altered since only small welding points were used to put thermocouples. The tank was equipped with 22 external wall thermocouples ( $\mathrm{K}$ type), protected from the direct radiative heat flux with steel caps. 8 thermocouples were arranged on a vertical pole to measure fluid temperatures. Two radiative heat flux sensors (CAPTEC, France) were disposed on the tank wall facing the fire, at a position determined theoretically as being the MHF place on the tank. 3 convective heat flux sensors (CAPTEC) were glued with a thin high temperature glue on the wall. The surface of this sensor was covered with a thin nickel polished surface in order to reflect any impacting radiative heat flux (emissivity 0.072 ). Since the sensors were at wall temperature, the sensors measured therefore only the convective heat flux transferred at this point. The internal pressure was measured with a pressure gauge. The test was performed during 20 minutes, and then the fire wall was turned off. The remaining LPG was vented and burned with an external flare.

\section{Results and discussion}

The radiative heat flux impacting the tank was recorded by two sensors. Fig. 8 reports the data: both curves correspond perfectly, which shows that the fire was symmetrical. The heat flux was not very constant since the natural gas pressure fluctuated strongly during the experiments. The maximum heat flux was recorded at the beginning of the trial. From this point, a slow decrease in the

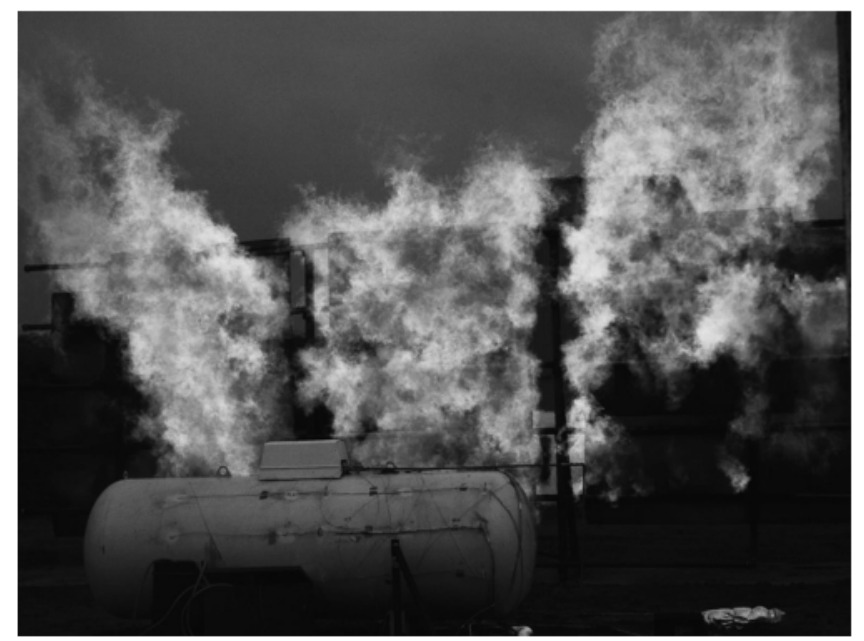

Fig. 7. Experimental setup.

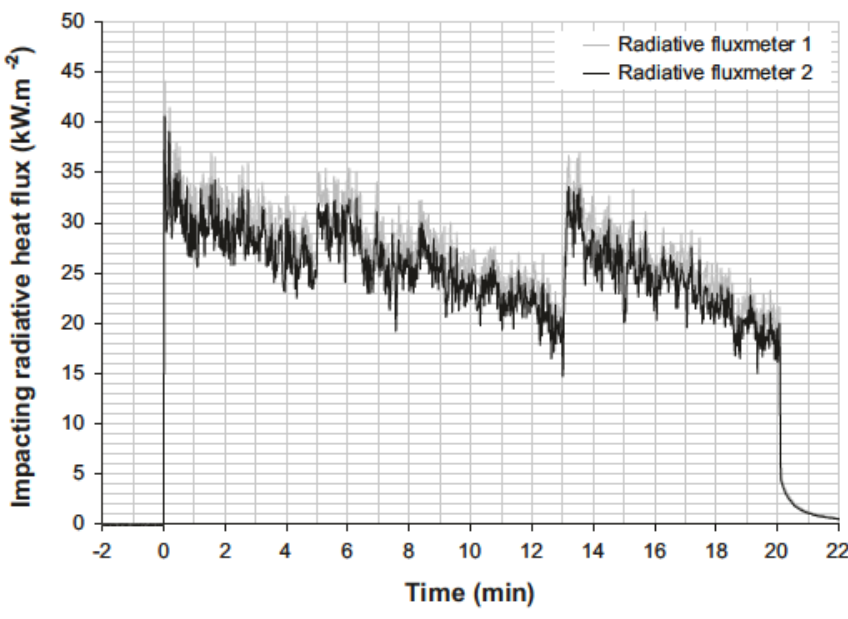

Fig. 8. Radiative heat flux on the LPG tank.

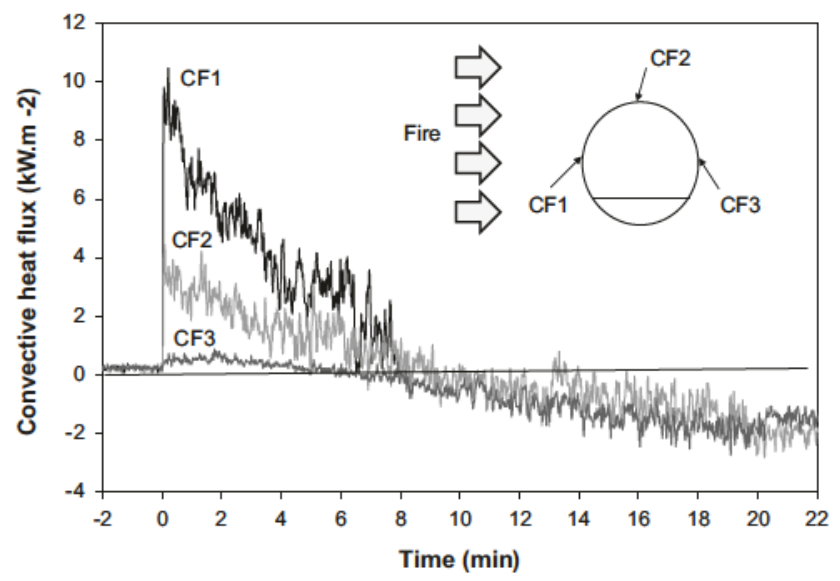

Fig. 9. Convective heat flux on the LPG tank.

pressure was noticed, and the radiative heat flux decreased to $16 \mathrm{~kW} \mathrm{~m}^{-2}$. The feed valve was then opened more, which enabled the heat flux to rise to $35 \mathrm{~kW} \mathrm{~m}^{-2}$. The average value of the impacting heat flux was calculated to be $26 \mathrm{~kW} \mathrm{~m}^{-2}$ during the experiment, which corresponds well with the theoretical requirement to represent the large crown forest fire burning $50 \mathrm{~m}$ from a tank (Table 2).

Convective flux sensors measured the heat transferred to the wall. Fig. 9 highlights these results, which are quite rare in literature data. Three different data sets are reported: one in front of the wall, one at the top of the tank, and one in the shadow of the firewall at the back of the tank. The convective heat flux is at its maximum at the beginning, when the tank wall is cold and the hot gases of the flames transfer heat to the wall. A maximum value of $10 \mathrm{~kW} \mathrm{~m}^{-2}$ was recorded, which is an important heat flux for convection. We consider that the convection was not only natural, but also forced since the jet effect of the natural gas flames could play a role at a distance of $3.8 \mathrm{~m}$. Even at the back of the tank, a small amount of heat was transferred $\left(800 \mathrm{~W} \mathrm{~m}^{-2}\right)$ which shows that hot gases bypassed the tank. During this time, the wall temperature increases and therefore the convective heat flux decreases. At $9 \mathrm{~min}$, the convective heat flux is zero, and the direction of heat transfer changes: the heat is transferred from the hot walls to the cooler combustion gases close to the wall.

The real heat transferred to the LPG tank is a balance of impacting and reflected radiative heat flux, emitted radiative heat flux, and convective heat flux. The remaining heat in then transferred to and through the steel wall. At the initial time, the 
real heat transferred to the LPG tank can be assumed to be close to $55 \mathrm{~kW} \mathrm{~m}^{-2}$ (emissivity of white paint taken 0.9 ). Fig. 10 reveals the external wall temperatures of the tank. Only the data recorded in front of the firewall are reported. Temperatures measured at the back are not reported here. In order to make the figure more readable, same shades of gray were chosen for sets of similar thermocouples. One single thermocouple was located under the tank (A), three sets of three thermocouples formed horizontal groups (B, C and D), both thermocouples at the end were grouped (E) as well as the top thermocouples (F). Temperature increase followed a classical curve until the fire was turned off. At this time, the maximum wall temperature was recorded to be $293^{\circ} \mathrm{C}$, in the middle of the D thermocouples group. This was theoretically expected due to the geometric configuration. This wall temperature was far below the safety criteria of $427^{\circ} \mathrm{C}$, and the steel remained quite strong. At this time, the internal pressure was recorded to be 14 barg. The pressure relief valve did not open, and the situation was safe.

Our experiment confirms that an LPG tank will not BLEVE if impacted by a $24 \mathrm{~kW} \mathrm{~m}^{-2}$ radiant heat flux, and confirms the criteria of the American Petroleum Institute, which state that if a tank with a pressure relief valve is impacted by a heat flux below $22 \mathrm{~kW} \mathrm{~m}^{-2}$, it should remain safe.

The scenario considered was a large crown fire with $40 \mathrm{~m}$ high flames, on a $100 \mathrm{~m}$ long forest edge. This scenario is very severe, most crown fires are reported with only 20 or $30 \mathrm{~m}$ high flames. A parametric study was then performed in order to assess the safety distance for an LPG tank, while varying the fire height and length as well as the distance between fire and tank wall. Results are reported in Fig. 11. The curves represent a configuration where the MHF equals $24 \mathrm{~kW} \mathrm{~m}^{-2}$. Other safety configurations can be analyzed on the basis of these results. The data reveal that for a wildfire with $20 \mathrm{~m}$ high flames, the safety distance is $26 \mathrm{~m}$ if the burning wall is $60 \mathrm{~m}$ long. This corresponds to the safety distance in Spain, and is in good agreement with Cohen [22], who studied the ignition criteria for house burning and considered the level of $31 \mathrm{~kW} \mathrm{~m}^{-2}$. Exposed to a fire with $20 \mathrm{~m}$ high flames, which is $50 \mathrm{~m}$ long, Cohen concludes that the safety distance is $28 \mathrm{~m}$. All fire scenarios located to the right of the parametric curves from Fig. 11 are safe for LPG tanks.

It is interesting to note that for close fires $(10 \mathrm{~m})$, the height of the fire does not play a strong role in the MHF: there is almost no difference between a $20 \mathrm{~m}$ and a $40 \mathrm{~m}$ high fire. This is obviously due to the view factor: a fire located very high on a burning tree does not radiate strongly on a the tank located at the base of the fire. However, at such a short distance, heat transfer by convection

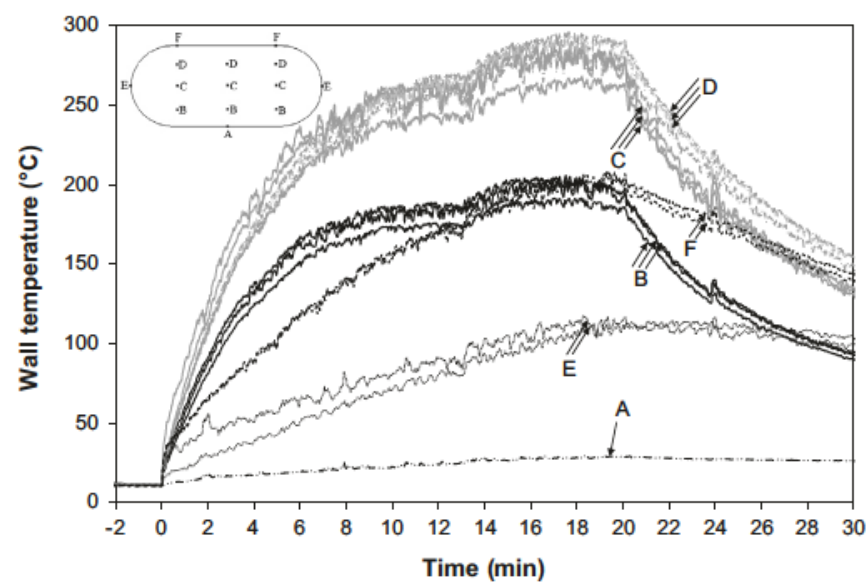

Fig. 10. Wall temperatures.

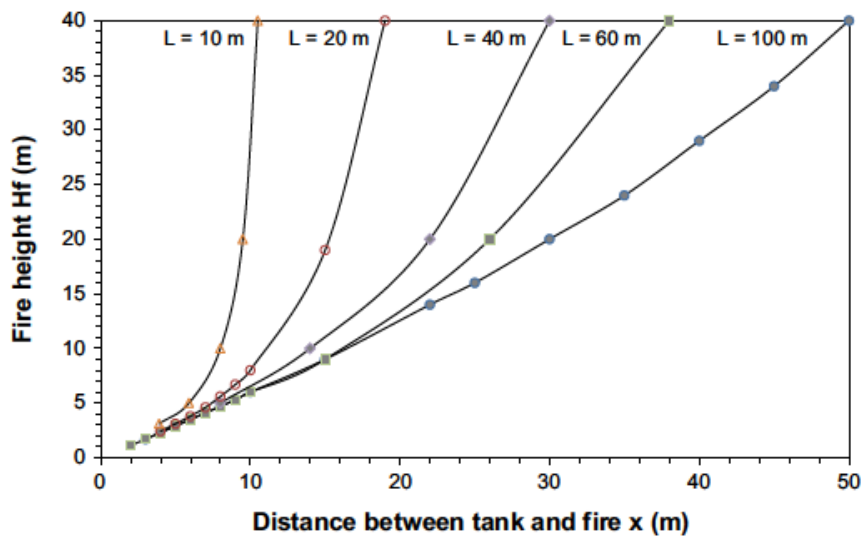

Fig. 11. Parametric study for LPG safety distance.

has to be taken into account, and can add a significant amount of heat to the tank.

\section{Conclusion}

Although a number of authors have studied the thermal radiation emitted by wildland fires, few have used this information as a basis for establishing zones in which people or houses are safe in the event of a fire, and no work has focused on the specific case of an LPG tank that might be located close to the forest.

Our study considered the case of a very strong crown fire (height $40 \mathrm{~m}$, length $100 \mathrm{~m}$ ) at a mandatory safety distance of $50 \mathrm{~m}$. The tank was theoretically expected to be impacted by a $24 \mathrm{~kW} \mathrm{~m}^{-2}$, which is slightly above the API safety criteria.

An experiment was performed at the Spadeadam test site in order to record the LPG tank behavior when impacted by a heat flux corresponding to a wildland crown fire. The average radiative impacting heat flux was measured to be $26 \mathrm{~kW} \cdot \mathrm{m}^{-2}$ with a highest intensity at $44 \mathrm{~kW} \mathrm{~m}^{-2}$. Wall temperature was recorded and remained below $427^{\circ} \mathrm{C}$, which falls within the safety criteria range. Internal pressure rose to $14 \mathrm{barg}$, but did not cause the pressure relief valve to open. The tank remained completely safe.

A parametric study proposes the safety distance for an LPG tank depending on the fire height and length, and the distance between the flames and the tank wall. In some cases, a safety distance of $30 \mathrm{~m}$ should be sufficient to avoid BLEVE.

The main conclusion of this study is that in accordance with the initial assumptions of this research, no BLEVE hazard may occur if the wildland fire remains $50 \mathrm{~m}$ from the tank.

\section{Acknowledgments}

The authors thank the CFBP (Comité Français du Butane Propane) for their financial support, and the GL Noble Denton Spadeadam test site for its valuable technical collaboration.

\section{References}

[1] G. Gettle, C.L. Rice, Criteria for Determining the Safe Separation Between Structures and Wildlands, Millpress, Rotterdam, 2002.

[2] H.C. Tran, J.D. Cohen, R.A. Chase, Modeling ignition of structures in wildland urban interface fires, in: Proceedings of the 1st International Fire and Materials Conference, Arlington, VA, 1992, pp. 253-262.

[3] B.W. Butler, J.D. Cohen, Firefighter safety zones: a theoretical model based on radiative heating, International Journal of Wild land Fire 8 (1998) 73-77.

[4] B.W. Butler, J.D. Cohen, Field verification of a firefighter safety zone model, in: Proceedings of the 2000 International Wildfire Safety Summit, 2000, pp. 10-12. 
[5] A.L. Sullivan, P.F. Ellis, L.K. Knight, A review of radiative heat flux models used in bushfire applications, International Journal of Wildland Fire 12 (2003) 101-110.

[6] Y. Billaud, A. Kaiss, J.L. Consalvi, B. Porterie, Monte Carlo estimation of therma radiation from wildland fires, International Journal of Thermal Sciences 50 (2011) 2-11.

[7] L. Zarate, J. Arnaldos, J. Casal, Establishing safety distances for wildland fires, Fire Safety Journal 43 (2008) 565-575.

[8] A.M. Birk, M.H. Cunningham, The boiling liquid expanding vapor explosion, Journal of Loss Prevention in the Process Industries 7 (1994) 474-480.

[9] A.M. Birk, D. Poirier, C. Davison, On the response of 500 gal propane tanks to a $25 \%$ engulfing fire, Journal of Loss Prevention in the Process Industries 19 (2006) 527-541.

[10] A.M. Birk, C. Davison, M. Cunningham, Blast overpressures from medium scale BLEVE tests, Journal of Loss Prevention in the Process Industries 20 (2007) 194-206.

[11] B. Genova, M. Silvestrini, F.J. Leon Trujillo, Evaluation of the blast-wave overpressure and fragments initial velocity for a BLEVE event via empirical correlations derived by a simplified model of released energy, Journal of Loss Prevention in the Process Industries 21 (2008) 110-117.

[12] J. Maillette, A.M. Birk, Influence of release conditions on BLEVE fireballs, American Society of Mechanical Engineers, Pressure Vessels and Piping Division(Publication) PVP 333 (1996) 147-152.

[13] J.F. Sacadura, Radiative heat transfer in fire safety science, Journal of Quantitative Spectroscopy and Radiative Transfer 93 (2005) 5-24.
[14] H.H. Wang, Analytical model for determining thermal radiance of fire plumes with implication to wildland fire, Combustion Science and Technology 181 (2009) 245-263.

[15] G. Parent, Z. Acem, S. Lechene, P. Boulet, Measurement of infrared radiation emitted by the flame of a vegetation fire, International Journal of Thermal Sciences 49 (2010) 555-562.

[16] L. Trabaud, Les feux de Forets, Mecanismes, Comportement et Environnement, 2nd ed., Aubervilliers: France-Sélection, Aubervilliers, France, 1992, ISBN: -85266-037-7.

[17] R. Leicester, Building technology to resist fire, flood and drought, in: Proceedings of the Ninth Invitation Symposium, Natural Distasters in Australia, Sydney, 1988.

[18] S. Tassios, D.R. Packham, An investigation of some thermal properties of four fabrics suitable for use in rural firefighting, National Centre for Rural Fire Research TEchnical Paper $n^{\circ} 1$, Chisholm Institue of Technology, (1984).

[19] J.H. McGuire, Heat Transfer by Radiation Fire Research special report $n^{\circ} 2$, in: Her Majesty's Stationery Office, London, 1953.

[20] K.G.T. Hollands, On the superposition rule for configuration factors, Journal of Heat Transfer 117 (1995) 241-245.

[21] C.J.H. Van den Bosch, R.A.P.M. Weterings, Methods for the Calculation of Physical Effects due to Release of Hazardous Materials (Liquids and Gases), third ed. Gevaarlijke Stoffen, 1997.

[22] J.D. Cohen, Relating flame radiation to home ignition using modeling and experimental crown fires, Canadian Joumal for Forestry Research 34 (2004) $1616-1626$ 